\title{
Electrochemical Performance of Chitosan Oligosaccharide/Carbon Nanotube Composite for Detection of Trace Copper(II) Ion
}

Tingkai Zhao*, Xianglin Ji, Wenbo Jin, Shasha Guo, Yuanbo Cheng, Xuan Wang, Alei Dang, Hao Li, Tiehu Li

The State Key Laboratory of Solidification Processing, Northwestern Polytechnical University, Xi'an 710072, China;

*E-mail: jixianglinnwpu@ outlook.com, ztk@nwpu.edu.cn

doi: $10.20964 / 2017.03 .35$

Received: 28 September 2016 / Accepted: 9 January 2017 / Published: 12 February 2017

Chitosan oligosaccharide (COS)/multi-walled carbon nanotube (MWCNT) composite was prepared by electrostatic self-assembly method. The thickness of COS uniformly enwrapped on the surface of MWCNTs is around $3.3 \mathrm{~nm}$. COS/MWCNT composites exhibit excellent electrochemical property in $1 \mathrm{mM}\left[\mathrm{Fe}(\mathrm{CN})_{6}\right]^{3-/ 4-}$ solution. The results showed that the composites with $10 \mathrm{wt} \%$ MWCNTs presented obvious redox peak and low impedance and have good electrochemical response. The redox peak currents were linear while the concentration of copper sulfate ranging from $2 \times 10^{-8}$ to $2 \times 10^{-6} \mathrm{M}$. The relationship between oxidation peak currents $\mathrm{I}(\mathrm{A})$ and $\mathrm{Cu}^{2+}$ concentration $\mathrm{C}(\mathrm{M})$ is: $i_{\mathrm{pk}}(\mathrm{A})=2.228$ $\times 10^{-6}+12.96 * \mathrm{C}(\mathrm{M})$,

Keywords: chitosan oligosaccharide (COS), multi-walled carbon nanotubes (MWCNTS), electrochemical properties, copper ion

\section{$\underline{\text { FULL TEXT }}$}

(C) 2017 The Authors. Published by ESG (www.electrochemsci.org). This article is an open access article distributed under the terms and conditions of the Creative Commons Attribution license (http://creativecommons.org/licenses/by/4.0/). 